\title{
Asthma Phenotypes in Childhood
}

DOI:

10.1080/1744666X.2017.1257940

\section{Document Version}

Accepted author manuscript

Link to publication record in Manchester Research Explorer

\section{Citation for published version (APA):}

Deliu, M., Belgrave, D., Sperrin, M., Buchan, I., \& Custovic, A. (2017). Asthma Phenotypes in Childhood. Expert review of clinical immunology, 13(7), 705-713. https://doi.org/10.1080/1744666X.2017.1257940

\section{Published in:}

Expert review of clinical immunology

\section{Citing this paper}

Please note that where the full-text provided on Manchester Research Explorer is the Author Accepted Manuscript or Proof version this may differ from the final Published version. If citing, it is advised that you check and use the publisher's definitive version.

\section{General rights}

Copyright and moral rights for the publications made accessible in the Research Explorer are retained by the authors and/or other copyright owners and it is a condition of accessing publications that users recognise and abide by the legal requirements associated with these rights.

\section{Takedown policy}

If you believe that this document breaches copyright please refer to the University of Manchester's Takedown Procedures [http://man.ac.uk/04Y6Bo] or contact uml.scholarlycommunications@manchester.ac.uk providing relevant details, so we can investigate your claim.

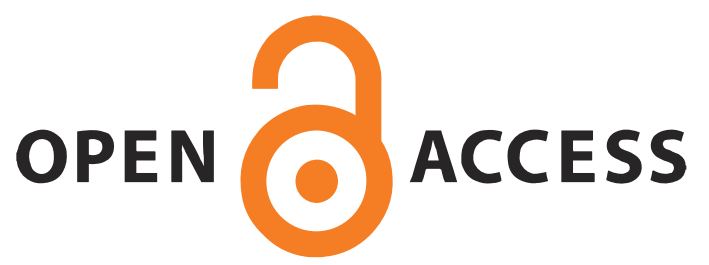




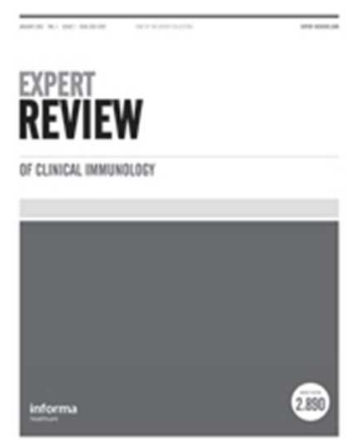

\section{Asthma Phenotypes in Childhood}

\begin{tabular}{|r|l|}
\hline Journal: & Expert Review of Clinical Immunology \\
\hline Manuscript ID & ERM-2016-0143.R1 \\
\hline Manuscript Type: & Reviews \\
\hline Keywords: & $\begin{array}{l}\text { asthma, childhood, asthma phenotypes, data-driven methods, endotype, } \\
\text { machine learning }\end{array}$ \\
\hline \multicolumn{2}{|l}{} \\
\hline
\end{tabular}

\section{SCHOLARONE"}

Manuscripts 


\title{
Asthma Phenotypes in Childhood
}

Matea Deliu ${ }^{1}$, Danielle Belgrave ${ }^{2}$, Matthew Sperrin ${ }^{1}$, Iain Buchan ${ }^{1}$, Adnan Custovic $^{2}$

1. Division of Informatics, Imaging and Data Sciences, Faculty of Biology, Medicine and Health, University of Manchester, Manchester, UK.

2. Department of Paediatrics, Imperial College of Science, Technology \& Medicine, London, UK.

\begin{abstract}
Introduction: Asthma is no longer thought of as a single disease, but rather a collection of varying symptoms expressing different disease patterns. One of the ongoing challenges is understanding the underlying pathophysiological mechanisms that may be responsible for the varying responses to treatment.

Areas Covered: This review provides an overview of our current understanding of the asthma phenotype concept in childhood and describes key findings from both conventional and data-driven methods.

Expert Commentary: With the vast amounts of data generated from cohorts, there is hope that we can elucidate distinct pathophysiological mechanisms, or endotypes. In return, this would lead to better patient stratification and disease management, thereby providing true personalised medicine.
\end{abstract}

Keywords: asthma phenotypes, data-driven methods, endotype, machine learning 


\section{Introduction}

Asthma is a common disease which has been rapidly increasing in both prevalence and incidence. The surge of new cases, particularly in the western world, can be in part attributed to rapid changes in lifestyle and environmental exposures. However, the exact extent of this environmental impact is yet to be fully understood. For the most part, asthma starts in early childhood, though some patients can develop more severe disease symptoms either in teenage years or adulthood; the incidence of new cases is lower in adults[1,2]. The variability in the expression of asthma symptoms observed within a clinical setting has prompted the move away from the concept that asthma is a single entity; it is now generally considered that asthma is an umbrella term for several distinct conditions that share common clinical features such as wheezing, cough, shortness of breath, and variable airflow obstruction[3].

A phenotype is defined as an observable property or trait that arises from the interaction of genes and environmental exposures. Phenotypes are therefore characteristics that can be directly observed and measured (either biochemically or physically)[4]. For example, in clinical terms 'trait' may refer to wheeze or lung function; wheeze can be auscultated and lung function can be measured, e.g. by spirometry. However, these traits can vary drastically in terms of the manner in which they are manifested between different patients, and relating them to underlying mechanisms would be essential to understand the pathology of the disease(s). With such variation in the clinical expression of asthma, the concept of 'endotype' has been proposed[5, 6]. Whereas the term 'phenotype' refers to an external, directly observable characteristic, an 'endotype' indicates a subtype of the disease with a distinct underlying pathophysiologic mechanism, which may in part explain the observed heterogeneity in phenotype manifestation[7]. As shown in Figure 1, our task in understanding asthma is to disentangle the multifarious phenotypes in an attempt to distinguish distinct subtypes which may in turn indicate the presence of distinct endotypes which have distinct causal mechanisms. Multiple 'endotypes' can therefore give rise to the same or similar phenotype[7], and this endotype-phenotype connection itself may not be a static characteristic. A level of complexity is added by the fact that some of the key phenotypes (e.g. eosinophilic inflammation) are highly variable in childhood[8].

The importance of identifying asthma endotypes (or subtype) is primarily for understanding disease mechanisms. Our current treatment guidelines are still guided primarily by symptoms and lung function, yet we have all seen that similar symptoms have different levels of response to commonly used treatments. Deciphering the cause of this heterogeneity would lead to better treatment targeting, and would be a step towards "precision" medicine. Furthermore, there is hope that this knowledge would pave the way for better predictive modelling based on risk factors and disease progression. In other words, if we can correctly categorise children into different subtypes at a young age, we will have insight into the developmental trajectory of the disease in order to apply preventative strategies. However, we have yet to fully discover all the modifiable factors that influence the natural course of the asthma-related diseases.

A wide array of methodologies have been utilised to enhance subtypying of asthma and allergic diseases in childhood. Such methods range from expert investigator-led approaches to identifying patterns and co-occurrence of symptoms which mimics the approach used within a clinical setting, to supervised statistical modelling approaches which aim to test hypothesised frameworks for disease profiles, and unsupervised data-driven statistical methods which take an agnostic view of the data in order to infer structure based 
on pattern recognition computer algorithms $[9,10]$. Combinations of supervised and unsupervised models allow us to incorporate prior clinical knowledge within a data-driven approach and can also enable us to evaluate the likelihood that our observed data is aligned to prior hypotheses or clinical assumptions. All of these methods have advanced our knowledge in this field in different ways. Subjective expert-driven approaches have been able to describe and externally validate what is seen in clinic, while data driven machine learning approaches are capitalizing on the wealth of data available by seeking to find patterns of disease and then applying that to the general population.

Our understanding of asthma heterogeneity is constantly evolving. In this review, we present our current knowledge of the subtypes in childhood asthma. We explain the clinical implications of phenotyping and subtyping asthma in childhood, as this is the critical period that is amenable to potential prevention strategies.

\section{$>>$ Insert Figure 1 here<<}

Figure 1: Schematic drawing of the asthma syndrome. BMI: body mass index

\section{Wheeze phenotypes}

The presence or absence of wheeze is one of the key determinants of asthma. Wheezing is associated with airflow obstruction due to airway narrowing. In children, this auscultatory finding is primarily an expression of large airway obstruction. Wheeze can manifest in various ways and at different time points in a child's life. However, it should be noted that not all wheeze can lead to asthma, particularly in those children below the age of 3 years. Within the last decade, there has been a surge of data describing various ways of identifying wheeze phenotypes in childhood. At the most general level, phenotypes have been characterised according to age of onset (early vs late), according to severity, or based on triggers (viral, allergen, or other).

\subsection{Wheeze phenotypes based on age of onset and remission (temporal pattern)}

Differentiating wheeze phenotypes by age of onset during childhood can give insight into the pattern of disease expression later in adulthood. The ability to predict both the timing (whether a child will develop wheezing early on or later in life) as well as subsequent profile of symptom development may allow us to pre-emptively manage such occurrence and severity. As a result, age of onset of wheeze and its persistence have become key determinants for identifying distinct wheeze subtypes.

\subsubsection{Early onset transient wheeze}

The first seminal paper to characterize wheeze and its natural history was by Martinez et al[11] in an unselected birth cohort based in Tucson, AZ. Using a subjective 
clinical approach based on the observed patterns of wheeze over time, 'transient-early onset wheeze' was defined as wheeze with onset before the age of three years, with subsequent resolution by age six years[11]. The authors hypothesized that transient early wheeze may be triggered by viral infections. These children initially had poorer lung function in infancy which later improved, although remaining lower compared to the control group.

The Manchester Asthma and Allergy Study (MAAS) used a longitudinal latent class model integrating data from both parental questionnaires and medical records to ascertain children's wheeze symptoms. This model represented a statistical data-driven approach which assigns children to their most probable latent (unobserved) cluster based on the patterns of wheeze at multiple time-points (Figure 2A). These clusters are hypothesised to represent distinct symptom profiles with distinct underlying pathophysiology. Using complementary data sources enabled the modelling of uncertainty in parental or physician diagnosis of wheeze. Similar to the Tuscan cohort, MAAS also identified a transient early wheeze group (wheezing from age 1-5). However, unlike Tuscan, they found that lung function in these children remained impaired compared to non-wheezers throughout childhood[12].

Using a similar statistical approach, but based only on parental reporting of wheeze, Henderson et al[13] of the Avon Longitudinal Study of Parents and Children (ALSPAC) (see figure 2) cohort identified a prolonged early wheezing group (wheezing from 6-54 months). Compared to the findings from the Tucson study, the prolonged-early phenotype is thought to be a more severe form of transient-early wheeze based on observed diminished lung function at age 8-9 years for this group of children. However early-life lung function was not available thus hindering evaluation as to whether there is a distinction in pre-morbid lung function for this group of children compared to the transient early wheezers. Indeed, as lung function measurements are difficult to obtain below the age of 2 years, many institutions are increasingly reluctant on labelling early wheeze as asthma. The results from the ALSPAC have been replicated using similar methodology in other cohorts [12, 14-17]. Within the various studies described, the definition and prevalence of early-onset wheeze varied between study groups (in part likely a consequence of the age at which data was collected). For example, the prevalence of early-onset wheeze in the Tucson study[11] was $19.9 \%$, and $23.5 \%$ in MAAS[18]. Using a solely data-driven approach, the proportion of children in MAAS[19] rose to $29.3 \%$, while ALSPAC reported $42.4 \%[13]$.

In most studies, the majority of children who wheezed early in infancy have symptom resolution in later childhood [11, 20-23]. Risk factors identified for transient early wheeze include exposure to tobacco smoke, day care attendance, virus infections, and family history of asthma[14, 24, 25]. Results have been inconsistent with regards to sex and position in sibship[25-27].

$>$ Insert Figure 2 Here<<

\subsubsection{Persistent wheeze}

Similar to transient wheezers, children with persistent wheeze start wheezing in early life; however, in contrast to transient wheezers, their symptoms do not resolve, but 
continue in later childhood[11]. One of the characteristics of persistent wheeze is diminished lung function by school age, with likely persistence to adulthood. Martinez et al [11] found that compared to controls (non-wheezers), children with persistent wheeze initially had normal lung function, but that lung function significantly worsened by age six years. This was also seen at age 11 years in a follow-up study[29]. These children were more likely to be atopic, have higher IgE levels, and be sensitized early on. Using similar subjective methods to characterise children, study groups from New Zealand[20] and Australia[30], observed that children who were categorised as persistent wheezers continued to wheeze into adulthood and had consistently lower lung function.

Availability of data from primary care medical records in the MAAS cohort[31] allowed stratification of persistent wheeze into two distinct subgroups: persistent controlled and persistent troublesome wheeze. Children with "troublesome" wheeze were more likely to have a high symptom burden despite high doses of inhaled corticosteroids. Belgrave et al[12] found that being highly atopic (whether to food or inhalant allergens) and having concurrent eczema were strong predictors of this phenotype. The persistent wheeze identified in ALSPAC showed a similar pattern though with weaker atopy associations[13]. Early identification of children who are at risk of persistent troublesome wheeze would allow for better management, and possible prevention to reduce the likelihood of persistence of troublesome symptoms into adulthood.

An intermediate onset wheeze (onset between 18-42 months) was identified in ALSPAC, though given the time of onset, this could be classified as early in other studies. Children in this category were more likely to be atopic (particularly to house dust mite and cat), have poor lung function, and subsequently be at risk of developing asthma in later childhood.

Atopic sensitization is a well-documented risk factor for both persistent wheezing [11-13] and the persistence of asthma from school-age to late teenage years[32]. However, Simpson et al have demonstrated that atopic sensitisation may not be a simple dichotomous trait, but rather a collection of several different atopic vulnerabilities[33]. Of the four distinct sensitization classes identified in this study, there was a strong association between only one of these classes (assigned as multiple early atopy) and persistent wheezing. Similar structure within the data on sensitisation, and identical association with persistent wheezing and asthma has been reported in the Isle of Wight study[34]. Using a similar approach, similar atopic patterns were identified in the Childhood Asthma Prevention Study (CAPS) from Australia, and asthma at age 8 was associated with mixed food (predominantly peanut) and inhalant sensitization[35]. However, such stratification of atopic sensitization requires the use of complex machine learning models on rich longitudinal data, and cross-sectional biomarkers of different atopic vulnerabilities will need to be discovered if this is to be translated into clinical practice. 


\subsubsection{Late onset wheeze}

Late onset wheeze is generally described as wheeze with onset after age three years which persists into later childhood. Atopic sensitization is consistently associated with this phenotype of wheeze across the different studies[12-14]. In ALSPAC, this sensitisation was grass pollen induced[13]. However, the association between late onset wheezing, lung function and bronchial hyperresponsiveness has differed between different studies. For example, MAAS and ALSPAC found that late onset wheeze was significantly associated with increased bronchial hyperresponsiveness and lung function impairment at age $6[13,31]$ while Prevention and Incidence of Asthma and Mite Allergy (PIAMA)[15] and Southampton Women's Study (SWS)[14] showed such association. Amongst environmental exposures, maternal smoking during pregnancy was risk factor for late onset wheezing in some[11, 36], but not all studies[12, 14].

Little is known on the stability of this phenotype, and further longitudinal follow-up is required to determine whether late-onset wheeze persists into adulthood.

\subsection{Wheeze phenotypes based on triggers}

Treatment of early childhood wheeze has been generally limited by the lack of evidence for the efficacy of most currently available treatments. To facilitate management of young children with wheezing, the European Task Force[37] proposed a clinical differentiation of early childhood wheezing into two subgroups: 'episodic viral wheeze (EVW)' and 'multiple trigger wheeze (MTW)'. EVW is described as intermittent seasonal wheeze episodes with occasional periods of 'feeling well'. Children labelled with episodic viral wheeze tend to be non-atopic with almost normal lung function, and symptoms tend to resolve by late childhood[38, 39]. Multiple trigger wheeze (MTW) is defined as "wheezing that shows discreet exacerbations, but also symptoms in between episodes[40]." Proposed triggers of MTW includes allergens, exercise, mist, crying, laughter etc. [37]. Of note, the major trigger of MTW are respiratory virus infections, making a clear distinction between EVW and MTW difficult. Both EVW and MTW are defined cross-sectionally at different ages, with severity of symptoms being accounted for by varying frequencies of wheezing episodes (more than three classified as frequent)[41, 42]. This classification was based on expert opinion, rather than solid data, and the implications were that ICS treatment would be more appropriate and effective for the MTW compared to EVW. However, neither of these two proposed "phenotypes" have been shown to be stable. For example, Schultz et al[43] showed that more than $50 \%$ of children change their phenotypic classification within 12 months of allocation into one of these two groups; EVW most frequently changed to MTW. However, a few years later, Schultz and Brand showed that regular use of corticosteroids had a modest effect on reducing symptoms in the EVW group[44]. Despite this, it is important to note that a phenotype-driven approach to treatment is still currently limited by our ability to accurately differentiate phenotypes and therefore the clinical utility is yet to be determined[44].

There have been attempts to validate this classification using data-driven techniques. For example, EVW was identified using latent class analysis in two studies from the Trousseau Asthma Program (TAP) [38, 45], while one study from Leicester, UK[39] suggested that the 'transient early wheeze' phenotype was very similar to EVW. A more severe type of EVW characterised by high FeNO levels and strong family history of asthma was described by Kappelle et al[46], and these children were at an increased risk of developing asthma at age five to 10 years, which was found to persist into adulthood[47]. 
The TAP group identified an atopic MTW in boys that was associated with severe wheezing and allergic comorbidities[45].

There have been attempts to reconcile phenotypes described through temporal patterns of symptoms and those based on triggers. For example, it has been suggested that transient early wheeze may correspond to EVW, and persistent wheeze to MTW [11, 39]. However, identifying children as having EVW/MTW is a relatively poor predictor of whether they would subsequently be classified as transient/persistent wheezers, with low positive predictive values[41, 48-50]. Depner and colleagues[16] sought to compare the data-driven wheeze phenotypes (early, transient, intermediate, late-onset, persistent) with the clinical classification of EVW/MTW by using a multi-country cohort of children from birth to 6 years of age and applying a longitudinal latent class model. Their results showed that approximately $60 \%$ of children with EVW were found to be within the transient early wheeze class implying that this phenotype is unlikely to encompass a chronic condition with poor lung function, but rather an initial response to viruses that eventually resolves[16]. However, the correlation with the LCA classes was poor. In contrast, $60-70 \%$ of children with MTW were either in the intermediate, late-onset, or persistent wheeze class. The correlation with the LCA classes was very high. Further to this, a variant of MTW was also identified and labelled recurrent unremitting wheeze (symptoms or wheeze without a cold on multiple occasions). This was characterised by impaired lung function, nonresponse to bronchodilators, and association with smoke exposure in utero. This group was also strongly correlated with late-onset thereby suggesting a distinct disease entity[16].

In the clinical community there is often an erroneous assumption that transient and EVW are relatively "benign", and persistent and MTW more troublesome. However, data from Manchester cohort have shown that almost $70 \%$ of all inhaled corticosteroids prescribed in the first year of life were prescribed to children in the transient wheeze group, although this class accounted for only one third of children who wheezed in the first year[12]. This would suggest that early-life transient wheezers may have more severe wheezing in infancy compared to those children who wheeze early, but go on to become persistent wheezers, and does not support the notion that transient and EVW are benign. These children may also be at risk of developing COPD in adulthood.

\section{Phenotypes of severe asthma}

The challenges in treatment of severe childhood wheezing/asthma due to high rates of non-responders suggests that children in the most severe category are either not taking their treatment, are undertreated, or do not respond to the currently available treatments. Although quantitatively small, this group of children consume a high proportion of resources[51] and therefore represent a significant economic burden.

In the US Severe Asthma Research Program (SARP), Fitzpatrick et al[52] used hierarchical clustering to identify four subgroups of severe asthmatic children differing in age of onset, lung function, FeNO and medication use. All subgroups were atopic, however, there was large variation in the magnitude of atopy. It is of note that the definition of asthma severity proposed by the ERS/ATS task force[53] was not fully applicable to any of the subgroups, despite initially using an ATS definition. In contrast, a study in Sweden did not find an association between atopy and severity of asthma[54]. They found that environmental factors, such as smoking, were significant risk factors for the severe asthma phenotype. 
The TAP group identified two other severe phenotypes, though within a more heterogeneous asthmatic population: 'asthma with severe exacerbations and multiple allergies', and 'severe asthma with bronchial obstruction' [55]. The first phenotype showed marked eosinophilic and basophilic inflammation, but the baseline $\mathrm{FEV}_{1}$ values were within normal range, though slightly lower than those for the mild asthmatic group. This is consistent with the observation that children can exacerbate frequently despite high

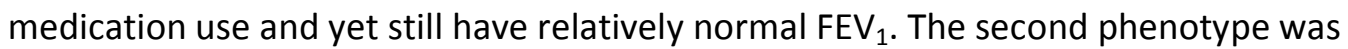
characterised by neutrophilia and high BMI. Additionally, this group of children had poorer lung function, though $\mathrm{FEV}_{1}$ was still within normal limits as depicted by guidelines, confirming that spirometry in children may not be a good marker of severe childhood asthma.

\section{Use of biomarkers to identify phenotypes}

The heterogeneity of asthma with regards to symptom expression, response to therapy, and lung function has prompted the search for objective markers with better diagnostic value which are able to distinguish distinct subtypes of asthma. The gold standard for assessing the extent of airway inflammation is through the use of bronchial biopsies, bronchoalveolar lavage, and sputum induction. These techniques, however, are too invasive for children, and there has to be a clear clinical indication with intended benefit for this method of assessment to be employed[56]. As a result, biomarkers in childhood asthma/wheezing have mostly been limited to serum/blood and breath. These biomarkers primarily assess eosinophilic or Th2 inflammation[57].

\subsection{Fractional concentration of exhaled Nitric Oxide (FeNO)}

Fractional concentration of Nitric Oxide has been widely used in children as it is noninvasive and relatively simple. Several studies have shown strong correlations between FeNO levels and blood/sputum eosinophils[58], IgE[59-61], and serum eosinophilic cationic protein[62, 63], with higher levels of FeNO denoting Th2-mediated inflammation and good response to inhaled corticosteroids[64]. 'Low' FeNO levels are thought to represent noneosinophillic asthma subtypes that are less likely to respond to ICS treatment[65]. The optimal threshold to differentiate what constitutes 'high' or 'low' levels of FeNO is still up for debate. The most recent guidelines suggest FeNO $<20 \mathrm{ppb}$ indicates poor response to inhaled corticosteroids, while FeNO $>35 \mathrm{ppb}$ indicates good response[66], but that serial measurements should be taken over time for monitoring. However, this recommendation is based on studies that had different cut off points and different positive/negative predictive values with respect to inhaled steroid effect. It is also important to keep in mind that FeNO levels reflect inflammation and not necessarily asthma, and so interpretation of results should be taken within context, particularly in the case of atopic comorbidities. As it stands, rather than identifying subtypes of wheezing, the clinical utility of FeNO is currently limited to that of a screening method for eosinophilic and Th2 mediated inflammation with some indication of steroid response, and may be used as a marker of adherence with ICS treatment.

\subsection{Exhaled Breath Condensate}

Exhaled breath condensate (EBC), thought to mirror airway lining fluid[67], is obtained by cooling exhaled air from children breathing normally for 10-15 minutes[68]. Potential biomarkers include $\mathrm{pH}$, markers of oxidative stress (8-isoprostane, hydrogen 
peroxide, aldehydes) and airway inflammation (eicosanoids, cytokines). Despite the lack of a standardised method, reference values, or proper validation[69], some interesting results have emerged. For example, 8-isoprostane has been found in increased quantities in both problematic and atopic asthmatic children despite ICS treatment[70, 71]. Th2 Cytokines, such as IL-4, are also increased in asthmatic children, especially those with concurrent atopy[72] and persistent wheeze[73]. This cytokine was also found to be a good marker for assessing asthma control[72]. Additionally, cytokine IL-5 has been shown to predict asthma exacerbations[74]. However, other studies have questioned the utility of EBC (in particular measuring $\mathrm{EBC} \mathrm{pH}$ ) in childhood asthma[75].

\subsection{Periostin}

Periostin is an emerging biomarker in Th2 inflammation in studies in adults. It is induced by IL-4 and IL-13 in airway epithelial cells and lung fibroblasts and thought to mediate collagen synthesis and fibrillogenesis[76, 77]. It has been suggested that high periostin is associated with good clinical response to corticosteroids in Th2 inflammation[78]. Recently, it has been used in clinical trials as a predictor of response to lebrikizumab (anti IL-13) [79]. However, periostin levels are higher in children compared to those in adults and change developmentally (likely due to bone turnover and growth), and it remains unclear whether periostin will be of use in phenotyping childhood wheezing and asthma.

\section{Asthma phenotypes and genetic studies}

Approaches for discovering genes connected to asthma have ranged from candidate gene association studies and genome-wide linkage studies, to more recent genome-wide association studies (GWAS). Several large studies (e.g. European GABRIEL consortium[80] and US EVE consortium[81]) identified a number of genetic associates of asthma in children (in particular in the region 17q21). However, the predictive value of these is low, with specificity being $75 \%$ and sensitivity only $35 \%$. Other genes (IL33, IL1RL1, IL18R1) have also been implicated in asthma development[82]. Most genetic studies defined "asthma" as parentally or patient-reported "doctor-diagnosed asthma". Unless genetic studies find better ways to distinguish between different asthma subtypes under this umbrella diagnosis at a population level, it will be difficult (if not impossible) to discover their unique underlying genetic risk factors, as any signal will be diluted by phenotypic heterogeneity[83]. It is worth emphasizing that when a much more precise and specific definition of early-life onset asthma with recurrent, severe exacerbations in pre-school age was used in a GWAS, identified associations had a considerably greater effect size (e.g. in 17q21 region), and novel susceptibility genes such as CDHR3 (cadherin-related family member 3, rs6967330, $\mathrm{C}_{529} \mathrm{Y}$ ]) were identified.[84] Subsequent studies have shown that CDHR3 may be a receptor for rhinovirus- $\mathrm{C}$, and that the same genetic variant which was linked with hospitalizations for early-onset childhood asthma in birth cohort studies also mediates enhanced RV-C binding and replication[85]. These studies provide indirect evidence that we need to move away from using umbrella term of "doctor-diagnosed asthma" in genetic studies, and that investigation of genetic associates of different wheeze phenotypes may render more informative findings. As an example, the ALSPAC investigators extended genetic association studies to include wheeze phenotypes which they identified previously, and found that 17q21 locus was associated with persistent and intermediate wheeze, but not with transient wheeze, atopy or lung function[86]. Combining data from the ALSPAC and the PIAMA 
cohort, Savenije et al found that IL1RL1 and IL33 SNPs were associated with intermediate and late-onset wheeze and that this was in the presence of early sensitization, thus suggesting that allergic sensitization, through the IL33-IL1RL1 pathway, may be the key driver to wheeze and subsequent asthma development[87].

A different approach using transcriptomic analysis of peripheral blood in children with viral induced wheeze and exacerbations has shown that there are distinct microRNA profiles in CD8+ T cells, with reduced regulation of microRNA146a/b and microRNA28$5 p[88]$.

Although we have been able to enhance our knowledge of genetic associations of wheeze phenotypes and asthma at a population level, we have still not been able to translate this knowledge to an individual level. This is partly due to the heterogeneous nature of childhood wheezing and asthma described above, but is also a consequence of gene-environment interactions whereby the genetic effect on asthma may be modified by certain environmental factors. Classical examples of the role of gene-environment interaction in modifying disease is finding that the impact of environmental endotoxin exposure on non-atopic wheeze and atopic sensitization was dependent on and modified by genetic variants in $C D 14[89,90]$, and studies demonstrating that the effect of day care on atopic wheezing is opposite among children with different variants of the TLR2 gene[91]. The approach to understanding asthma within the complex context of gene-environment interactions may be an incentive utilise a candidate gene approach based on sound epidemiological principles of causality[92].

\section{Expert commentary: lack of cohesive methodology for understanding asthma phenotypes in childhood}

There is clear lack of standardisation in defining childhood wheezing illness and asthma which is leading to the inconsistent findings with respect to the genetic, environmental and physiological risk factors associated with this disease. In the last few years, a plethora of divergent statistical methods have been used in an attempt to understand the natural history of childhood wheezing illness. Although, by definition, all these techniques find patterns within a dataset and categorise them accordingly, there is no unified statistical method, leading to inconsistency in results of studies using different datadriven approaches. This is exacerbated by the problem of inconsistent use of variables in different analyses and inconsistencies in the data collection process itself. Indeed, this could explain the sizeable variation in the proportion of children assigned to these wheeze phenotypes among published studies (see Belgrave et al[83] for table breakdown). This may be a reflection of both the different time points at which data was collected and the inherent symptom patterns among the dataset due to differences in population. Therefore, results from statistical and machine learning approaches need to be interpreted within a larger clinical context, and it needs to be emphasized that although such an approach can be used to generate hypotheses, it remains an exploratory rather than confirmatory approach to understanding subtypes of disease, and therefore clinical interpretation and external epidemiological validation is essential.

The large quantity and ready availability of data, while posing many challenges, also presents an opportunity to understand underlying disease heterogeneity with greater certainty. This is because a quantitatively increased volume of data gives us the ability to distinguish between "data signal" from "noise due to random variation" more accurately. Advances in computational power facilitate data visualisation and pattern recognition in 
high-dimensional data with greater speed and accuracy. Combined with increased computational power and advances in statistical methods, the emerging field of systems biology, which combines biomarkers, genomics, metabolomics, proteomics and computational mathematics, may enable better identification of pathophysiology underpinning disease subtypes. Integrating all these components from different cohorts and datasets, while including developmental patterns of symptoms, may initially identify common characteristics on a wider population level, with the ultimate goal of better understanding the disease on an individual level.

\section{Five-year view: clinical implications of defining asthma phenotypes in childhood}

There has been considerable progress in our understanding of the heterogeneity of asthma. Phenotyping asthma has started to provide a framework for further research into subtyping based on specific mechanisms. What has been shown here is that asthma can no longer be considered a single disease. Phenotyping in children can be either based on age of onset, triggers, severity, or symptoms. The clinical relevance of this would then be seen taking it one step further and analysing how each child's disease pattern develops over time and tailoring treatment accordingly. This is in stark contrast to the current approach where it is assumed that one drug treats all.

Classifying children into groups of similar observable characteristics and features will enable better understanding and subsequent classification into subtypes that represent the genetic, environmental, and biomarker make-up of the disease. Once this has been achieved, we can then follow-up longitudinally over time in order to assess stability, remission, and new onset of disease.

The ultimate aim is to be one step closer to personalised medicine which would provide early prevention and/or tailored treatment leading to more efficient use of resources and more efficacious control of disease in children. However, we are still not ready to apply this to every day clinical practice.

\section{Key Issues}

- Asthma is not a single disease

- Various asthma phenotypes have been proposed using subjective and data driven methods

- Wheeze is the most common manifestation of asthma syndrome, and both crosssectional and longitudinal studies have enhanced our knowledge on the natural history

- Using different approaches, wheeze phenotypes have been described using symptoms, triggers, severity, and age of onset

- Deciphering different subtypes at population level will lead to discovery of the underlying mechanisms

- The ultimate aim is to enable proper treatment targeting, enhance treatment monitoring, and apply early preventative strategies 


\section{Funding}

$M$ Deliu is supported in part by the Medical Research Council Health eResearch Centre (HeRC) grant MR/K006665/1. D Belgrave is supported by the Medical Research Council Career Development Award in Biostatistics, grant MR/M015181/1. A Custovic reports grants from the Medical Research Council, JP Moulton Charitable Foundation and the North West Lung Research Centre Charity.

\section{Declaration of Interests}

A Custovic reports personal fees from ThermoFisher, Regeneron/Sanofi and Novartis, outside of the submitted work. The authors have no other relevant affiliations or financial involvement with any organization or entity with a financial interest in or financial conflict with the subject matter or materials discussed in the manuscript apart from those disclosed.

\section{References}

Reference annotations

* Of interest

** Of considerable interest

1. Bjerg, A., et al., Time trends in asthma and wheeze in Swedish children 1996-2006: prevalence and risk factors by sex. Allergy, 2010. 65(1): p. 48-55.

2. Ronmark, E., et al., The Obstructive Lung Disease in Northern Sweden (OLIN) longitudinal paediatric study I--the first 10 years. Clin Respir J, 2008. 2 Suppl 1: p. 2633.

3. Belgrave, D., A. Simpson, and A. Custovic, Challenges in interpreting wheeze phenotypes: the clinical implications of statistical learning techniques. Am J Respir Crit Care Med, 2014. 189(2): p. 121-3.

4. Wenzel, S.E., Asthma phenotypes: the evolution from clinical to molecular approaches. Nat Med, 2012. 18(5): p. 716-25.

5. Anderson, G.P., Endotyping asthma: new insights into key pathogenic mechanisms in a complex, heterogeneous disease. Lancet, 2008. 372(9643): p. 1107-1119.

6. Lotvall, J., et al., Asthma endotypes: a new approach to classification of disease entities within the asthma syndrome. J Allergy Clin Immunol, 2011. 127(2): p. 355-60.

7. Custovic, A., et al., The Study Team for Early Life Asthma Research (STELAR) consortium 'Asthma e-lab': team science bringing data, methods and investigators together. Thorax, 2015. 70(8): p. 799-801.

8. Fleming, L., et al., Sputum inflammatory phenotypes are not stable in children with asthma. Thorax, 2012. 67(8): p. 675-81.

9. Deliu, M., et al., Identification of Asthma Subtypes Using Clustering Methodologies. Pulm Ther, 2016. 2: p. 19-41.

10. Howard, R., et al., Distinguishing Asthma Phenotypes Using Machine Learning Approaches. Curr Allergy Asthma Rep, 2015. 15(7): p. 38.

11. Martinez, F.D., et al., Asthma and wheezing in the first six years of life. The Group Health Medical Associates. N Engl J Med, 1995. 332(3): p. 133-8. 
12. Belgrave, D.C., et al., Joint modeling of parentally reported and physician-confirmed wheeze identifies children with persistent troublesome wheezing. J Allergy Clin Immunol, 2013. 132(3): p. 575-583 e12.

13. Henderson, J., et al., Associations of wheezing phenotypes in the first 6 years of life with atopy, lung function and airway responsiveness in mid-childhood. Thorax, 2008. 63(11): p. 974-80.

14. Collins, S.A., et al., Validation of novel wheeze phenotypes using longitudinal airway function and atopic sensitization data in the first 6 years of life: evidence from the Southampton Women's survey. Pediatr Pulmonol, 2013. 48(7): p. 683-92.

15. Savenije, O.E., et al., Comparison of childhood wheezing phenotypes in 2 birth cohorts: ALSPAC and PIAMA. J Allergy Clin Immunol, 2011. 127(6): p. 1505-12 e14.

16. Depner, M., et al., Clinical and epidemiologic phenotypes of childhood asthma. American journal of respiratory and critical care medicine, 2014. 189(2): p. 129-138.

17. Chen, Q., et al., Using latent class growth analysis to identify childhood wheeze phenotypes in an urban birth cohort. Annals of Allergy, Asthma \& Immunology, 2012. 108(5): p. 311-315.

18. Lowe, L.A., et al., Wheeze phenotypes and lung function in preschool children. Am J Respir Crit Care Med, 2005. 171(3): p. 231-7.

19. Belgrave, D.C.M., et al., Trajectories of lung function during childhood. American journal of respiratory and critical care medicine, 2014. 189(9): p. 1101-9.

20. Sears, M.R., et al., A longitudinal, population-based, cohort study of childhood asthma followed to adulthood. N Engl J Med, 2003. 349(15): p. 1414-22.

21. Morgan, W.J., et al., Outcome of asthma and wheezing in the first 6 years of life: follow-up through adolescence. Am J Respir Crit Care Med, 2005. 172(10): p. 1253-8.

22. Turner, S.W., et al., Infants with flow limitation at 4 weeks: outcome at 6 and 11 years. Am J Respir Crit Care Med, 2002. 165(9): p. 1294-8.

23. Lau, S., et al., Transient early wheeze is not associated with impaired lung function in 7-yr-old children. Eur Respir J, 2003. 21(5): p. 834-41.

24. Granell, R., J.A. Sterne, and J. Henderson, Associations of different phenotypes of wheezing illness in early childhood with environmental variables implicated in the aetiology of asthma. PLoS One, 2012. 7(10): p. e48359.

25. Stein, R.T. and F.D. Martinez, Asthma phenotypes in childhood: lessons from an epidemiological approach. Paediatr Respir Rev, 2004. 5(2): p. 155-61.

26. Scott, M., et al., Understanding the nature and outcome of childhood wheezing. Eur Respir J, 2009. 33(3): p. 700-1.

27. Kurukulaaratchy, R.J., et al., Are influences during pregnancy associated with wheezing phenotypes during the first decade of life? Acta Paediatr, 2005. 94(5): p. 553-8.

28. Henderson, J., et al., Associations of wheezing phenotypes in the first 6 years of life with atopy, lung function and airway responsiveness in mid-childhood. Thorax, 2008. 63(11): p. 974-80.

29. Stern DA, M.W., Taussig LM, Wright AL, Halonen M, Martinez FD, Lung function at age 11 in relation to early wheezing. American journal of respiratory and critical care medicine, 1999. 195: p. A148.

30. Phelan, P.D., C.F. Robertson, and A. Olinsky, The Melbourne Asthma Study: 19641999. J Allergy Clin Immunol, 2002. 109(2): p. 189-94. 
31. Belgrave, D.C.M., et al., Joint modeling of parentally reported and physicianconfirmed wheeze identifies children with persistent troublesome wheezing. The Journal of allergy and clinical immunology, 2013. 132(3): p. 575-583.e12.

32. Andersson, M., et al., Remission and persistence of asthma followed from 7 to 19 years of age. Pediatrics, 2013. 132(2): p. e435-42.

33. Simpson, A., et al., Beyond atopy: multiple patterns of sensitization in relation to asthma in a birth cohort study. American journal of respiratory and critical care medicine, 2010. 181(11): p. 1200-1206.

34. Lazic, N., et al., Multiple atopy phenotypes and their associations with asthma: similar findings from two birth cohorts. Allergy, 2013. 68(6): p. 764-70.

35. Garden, F.L., et al., Atopy phenotypes in the Childhood Asthma Prevention Study (CAPS) cohort and the relationship with allergic disease: clinical mechanisms in allergic disease. Clin Exp Allergy, 2013. 43(6): p. 633-41.

36. Sherriff, A., et al., Risk factor associations with wheezing patterns in children followed longitudinally from birth to 3(1/2) years. Int J Epidemiol, 2001. 30(6): p. 1473-84.

37. Brand, P.L., et al., Definition, assessment and treatment of wheezing disorders in preschool children: an evidence-based approach. Eur Respir J, 2008. 32(4): p. 1096110.

38. Just, J., et al., Wheeze phenotypes in young children have different courses during the preschool period. Ann Allergy Asthma Immunol, 2013. 111(4): p. 256-261 e1.

39. Spycher, B.D., et al., Distinguishing phenotypes of childhood wheeze and cough using latent class analysis. Eur Respir J, 2008. 31(5): p. 974-81.

40. Schultz, A. and P.L. Brand, Episodic viral wheeze and multiple trigger wheeze in preschool children: a useful distinction for clinicians? Paediatr Respir Rev, 2011. 12(3): p. 160-4.

41. Caudri, D., et al., Predicting the long-term prognosis of children with symptoms suggestive of asthma at preschool age. J Allergy Clin Immunol, 2009. 124(5): p. 90310 e1-7.

42. Tromp, II, et al., Dietary patterns and respiratory symptoms in pre-school children: the Generation R Study. Eur Respir J, 2012. 40(3): p. 681-9.

43. Schultz, A., et al., The transient value of classifying preschool wheeze into episodic viral wheeze and multiple trigger wheeze. Acta Paediatr, 2010. 99(1): p. 56-60.

44. $\quad * *$ Schultz, A. and P.L. Brand, Phenotype-directed treatment of pre-school-aged children with recurrent wheeze. J Paediatr Child Health, 2012. 48(2): p. E73-8.

Collates results on phenotype-directed treatment in chindren

45. Just, J., et al., Novel severe wheezy young children phenotypes: boys atopic multipletrigger and girls nonatopic uncontrolled wheeze. J Allergy Clin Immunol, 2012. 130(1): p. 103-10 e8.

46. Kappelle, L. and P.L. Brand, Severe episodic viral wheeze in preschool children: High risk of asthma at age 5-10 years. Eur J Pediatr, 2012. 171(6): p. 947-54.

47. Goksor, E., et al., Asthma symptoms in early childhood--what happens then? Acta Paediatr, 2006. 95(4): p. 471-8.

48. Frank, P.I., et al., Long term prognosis in preschool children with wheeze: longitudinal postal questionnaire study 1993-2004. BMJ, 2008. 336(7658): p. 1423-6.

49. Devulapalli, C.S., et al., Severity of obstructive airways disease by age 2 years predicts asthma at 10 years of age. Thorax, 2008. 63(1): p. 8-13. 
50. Matricardi, P.M., et al., Wheezing in childhood: incidence, longitudinal patterns and factors predicting persistence. Eur Respir J, 2008. 32(3): p. 585-92.

51. Godard, P., et al., Costs of asthma are correlated with severity: a 1-yr prospective study. Eur Respir J, 2002. 19(1): p. 61-7.

52. Fitzpatrick, A.M., et al., Heterogeneity of severe asthma in childhood: confirmation by cluster analysis of children in the National Institutes of Health/National Heart, Lung, and Blood Institute Severe Asthma Research Program. J Allergy Clin Immunol, 2011. 127(2): p. 382-389 e1-13.

53. Chung, K.F., et al., International ERS/ATS guidelines on definition, evaluation and treatment of severe asthma. Eur Respir J, 2014. 43(2): p. 343-73.

54. Konradsen, J.R., et al., Problematic severe asthma: a proposed approach to identifying children who are severely resistant to therapy. Pediatr Allergy Immunol, 2011. 22(1 Pt 1): p. 9-18.

55. Just, J., et al., Two novel, severe asthma phenotypes identified during childhood using a clustering approach. Eur Respir J, 2012. 40(1): p. 55-60.

56. Vijverberg, S.J., et al., Clinical utility of asthma biomarkers: from bench to bedside. Biologics, 2013. 7: p. 199-210.

57. Loutsios, C., et al., Biomarkers of eosinophilic inflammation in asthma. Expert Rev Respir Med, 2014. 8(2): p. 143-50.

58. Malinovschi, A., et al., Simultaneously increased fraction of exhaled nitric oxide levels and blood eosinophil counts relate to increased asthma morbidity. J Allergy Clin Immunol, 2016.

59. Brussee, J.E., et al., Exhaled nitric oxide in 4-year-old children: relationship with asthma and atopy. Eur Respir J, 2005. 25(3): p. 455-61.

60. Romero, K.M., et al., Role of exhaled nitric oxide as a predictor of atopy. Respir Res, 2013. 14: p. 48.

61. Scott, M., et al., Influence of atopy and asthma on exhaled nitric oxide in an unselected birth cohort study. Thorax, 2010. 65(3): p. 258-62.

62. Mogensen, I., et al., Simultaneously elevated exhaled nitric oxide and serum-ECP relate to recent asthma events in asthmatics in a cross sectional population based study. Clin Exp Allergy, 2016.

63. Warke, T.J., et al., Exhaled nitric oxide correlates with airway eosinophils in childhood asthma. Thorax, 2002. 57(5): p. 383-7.

64. Mahr, T.A., J. Malka, and J.D. Spahn, Inflammometry in pediatric asthma: a review of fractional exhaled nitric oxide in clinical practice. Allergy Asthma Proc, 2013. 34(3): p. 210-9.

65. Ludviksdottir, D., et al., Clinical aspects of using exhaled NO in asthma diagnosis and management. Clin Respir J, 2012. 6(4): p. 193-207.

66. Dweik, R.A., et al., An official ATS clinical practice guideline: interpretation of exhaled nitric oxide levels (FENO) for clinical applications. Am J Respir Crit Care Med, 2011. 184(5): p. 602-15.

67. Hunt, J., Exhaled breath condensate: an evolving tool for noninvasive evaluation of lung disease. J Allergy Clin Immunol, 2002. 110(1): p. 28-34.

68. Baraldi, E. and S. Carraro, Exhaled NO and breath condensate. Paediatr Respir Rev, 2006. 7 Suppl 1: p. S20-2.

69. Loukides, S., et al., Exhaled breath condensate in asthma: from bench to bedside. Curr Med Chem, 2011. 18(10): p. 1432-43. 
70. Carraro, S., et al., EIA and GC/MS analysis of 8-isoprostane in EBC of children with problematic asthma. Eur Respir J, 2010. 35(6): p. 1364-9.

71. Baraldi, E., et al., Cysteinyl leukotrienes and 8-isoprostane in exhaled breath condensate of children with asthma exacerbations. Thorax, 2003. 58(6): p. 505-9.

72. Robroeks, C.M., et al., Exhaled nitric oxide and biomarkers in exhaled breath condensate indicate the presence, severity and control of childhood asthma. Clin Exp Allergy, 2007. 37(9): p. 1303-11.

73. van de Kant, K.D., et al., Elevated inflammatory markers at preschool age precede persistent wheezing at school age. Pediatr Allergy Immunol, 2012. 23(3): p. 259-64.

74. Robroeks, C.M., et al., Prediction of asthma exacerbations in children: results of a one-year prospective study. Clin Exp Allergy, 2012. 42(5): p. 792-8.

75. Nicolaou, N.C., et al., Exhaled breath condensate $\mathrm{pH}$ and childhood asthma: unselected birth cohort study. Am J Respir Crit Care Med, 2006. 174(3): p. 254-9.

76. Sidhu, S.S., et al., Roles of epithelial cell-derived periostin in TGF-beta activation, collagen production, and collagen gel elasticity in asthma. Proc Natl Acad Sci U S A, 2010. 107(32): p. 14170-5.

77. Norris, R.A., et al., Periostin regulates collagen fibrillogenesis and the biomechanical properties of connective tissues. J Cell Biochem, 2007. 101(3): p. 695-711.

78. Woodruff, P.G., et al., Genome-wide profiling identifies epithelial cell genes associated with asthma and with treatment response to corticosteroids. Proc Natl Acad Sci U S A, 2007. 104(40): p. 15858-63.

79. Corren, J., et al., Lebrikizumab treatment in adults with asthma. N Engl J Med, 2011. 365(12): p. 1088-98.

80. Moffatt, M.F., et al., A large-scale, consortium-based genomewide association study of asthma. N Engl J Med, 2010. 363(13): p. 1211-21.

81. Torgerson, D.G., et al., Meta-analysis of genome-wide association studies of asthma in ethnically diverse North American populations. Nat Genet, 2011. 43(9): p. 887-92.

82. Grotenboer, N.S., et al., Decoding asthma: translating genetic variation in IL33 and IL1RL1 into disease pathophysiology. J Allergy Clin Immunol, 2013. 131(3): p. 856-65.

83. Belgrave, D.C., A. Custovic, and A. Simpson, Characterizing wheeze phenotypes to identify endotypes of childhood asthma, and the implications for future management. Expert Rev Clin Immunol, 2013. 9(10): p. 921-36.

84. Bonnelykke, K., et al., A genome-wide association study identifies CDHR3 as a susceptibility locus for early childhood asthma with severe exacerbations. Nat Genet, 2014. 46(1): p. 51-5.

85. Bochkov, Y.A., et al., Cadherin-related family member 3, a childhood asthma susceptibility gene product, mediates rhinovirus $C$ binding and replication. Proc Natl Acad Sci U S A, 2015. 112(17): p. 5485-90.

86. Granell, R., et al., Examination of the relationship between variation at 17q21 and childhood wheeze phenotypes. J Allergy Clin Immunol, 2013. 131(3): p. 685-94.

87. Savenije, O.E., et al., Association of IL33-IL-1 receptor-like 1 (IL1RL1) pathway polymorphisms with wheezing phenotypes and asthma in childhood. J Allergy Clin Immunol, 2014. 134(1): p. 170-7.

88. Tsitsiou, E., et al., Transcriptome analysis shows activation of circulating CD8+ T cells in patients with severe asthma. J Allergy Clin Immunol, 2012. 129(1): p. 95-103. 
89. Simpson, A., et al., Endotoxin exposure, CD14, and allergic disease: an interaction between genes and the environment. Am J Respir Crit Care Med, 2006. 174(4): p. 386-92.

90. Simpson, A. and F.D. Martinez, The role of lipopolysaccharide in the development of atopy in humans. Clin Exp Allergy, 2010. 40(2): p. 209-23.

91. Custovic, A., et al., Effect of day care attendance on sensitization and atopic wheezing differs by Toll-like receptor 2 genotype in 2 population-based birth cohort studies. J Allergy Clin Immunol, 2011. 127(2): p. 390-397 e1-9.

92. Tabor, H.K., N.J. Risch, and R.M. Myers, Candidate-gene approaches for studying complex genetic traits: practical considerations. Nat Rev Genet, 2002. 3(5): p. 391-7.

Figure Legends:

Figure 1: Schematic drawing of the asthma syndrome. BMI: body mass index

Figure 2: Comparison of wheeze phenotypes from Manchester Asthma and Allergy Study (MAAS) and Avon Longitudinal Study of Parents and Children (ALSPAC).

Adapted and modified with permission from J Allergy Clin Immunol, 132(3), Danielle, Belgrave, Simpson et al., Joint modeling of parentally reported and physician-confirmed wheeze identifies children with persistent troublesome wheezing. p. 575-583, Copyright 2013 [12] and from Thorax 63(11), Henderson, Granell, Heron et al., Associations of wheezing phenotypes in the first 6 years of life with atopy, lung function and airway responsiveness in mid-childhood: p. 974-80, Copyright 2008, with permission from BMJ Publishing Group Ltd [28]. 


\section{Asthma Syndrome}

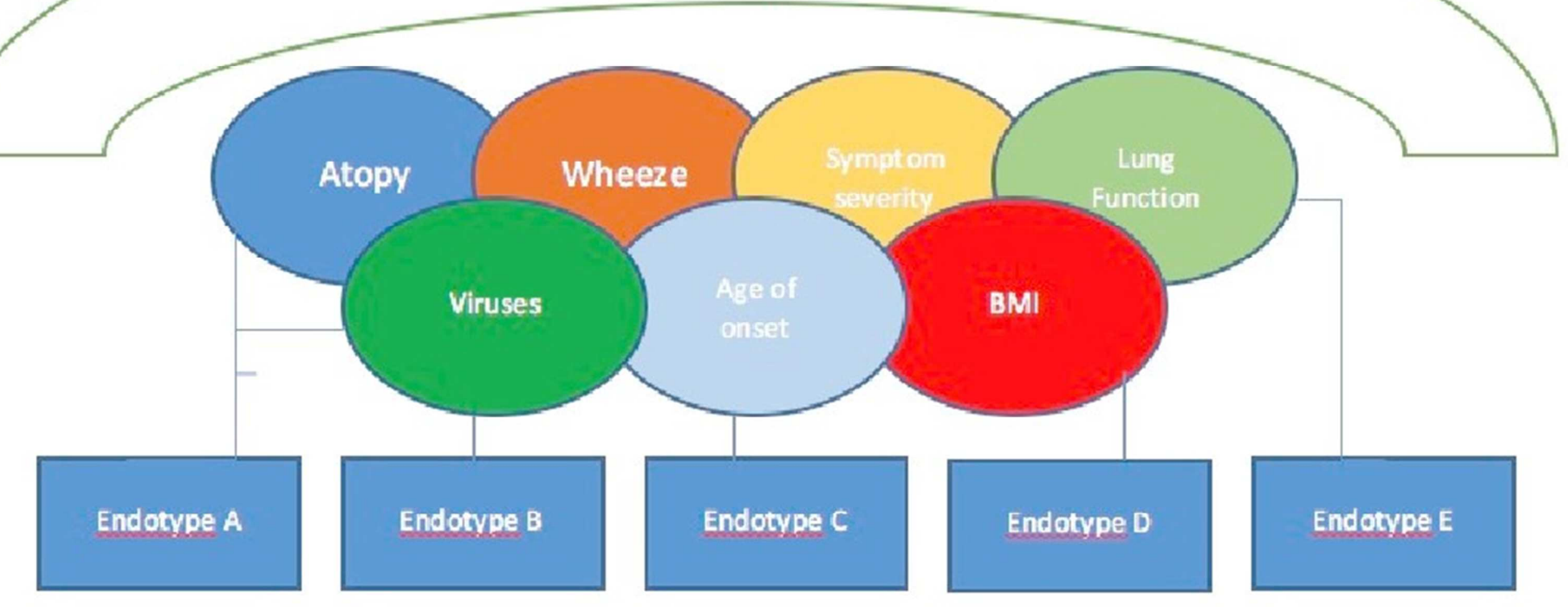

\section{Phenotypes}




\section{Page 19 of 19}
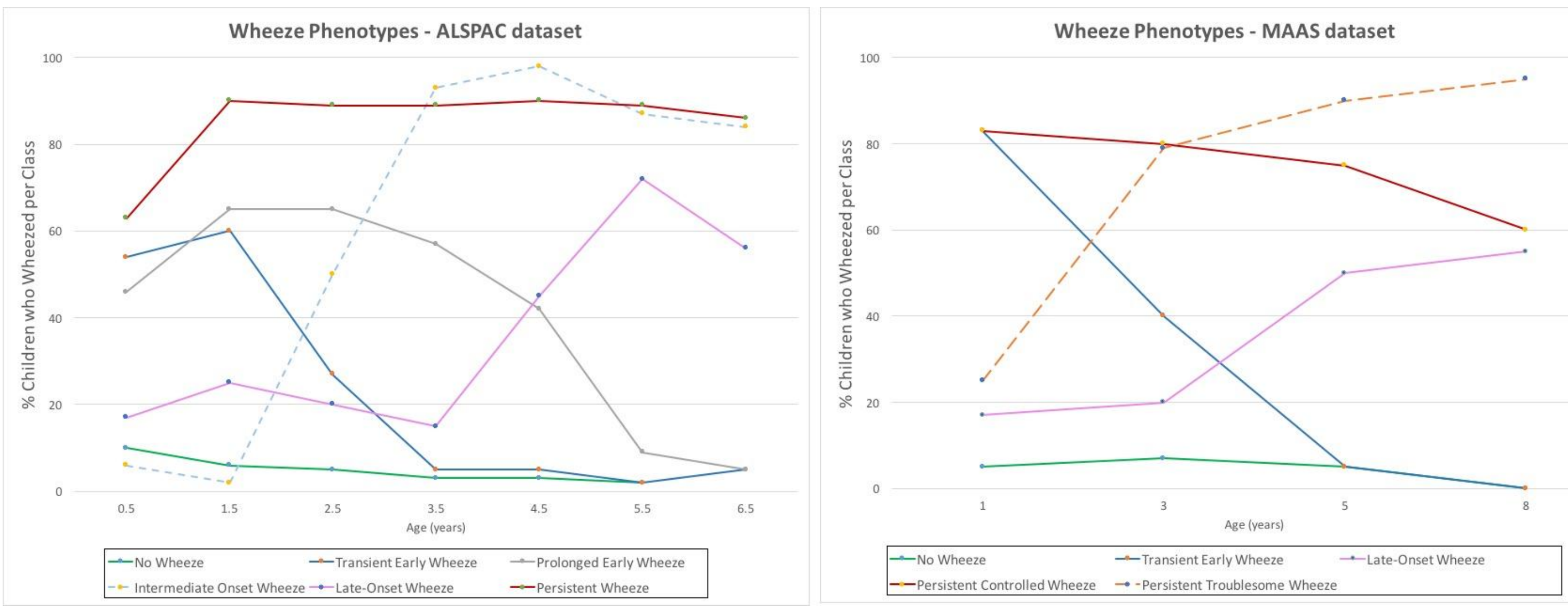

URL: https://mc.manuscriptcentral.com/erm Email: Alexander.Dearman@informa.com 